\title{
Financing and design innovation in rural domestic rainwater harvesting in Madagascar
}

Harry Chaplin and Hugo Legge

\begin{abstract}
Rural water supply interventions in low-resource settings often suffer from poor functionality. The use of technologies and financing approaches, that are out of step with the communities that they target, are primary drivers of this breakdown in supply. This paper describes a pilot study from south-east Madagascar that provides rural households with access to a water source at the home through the sale of rainwater harvesting systems. Results from the pilot show that households were prepared to pay a significant contribution towards establishing a household water supply despite being located in a low-resource, water-abundant region. Over a payback period of six months, zero households defaulted on loans that covered 57 per cent of the costs for materials and transport. Water quality tests demonstrated that the systems were capable of providing water with low levels of microbial contamination (median $C F U / 100 \mathrm{ml}=7$ ). High levels of adherence to operation and maintenance schedules suggest that people were capable and motivated to maintain and use their systems.
\end{abstract}

Keywords: rainwater harvesting, Madagascar, rural water supply, demand responsive approaches, innovative financing, supported self-supply

THIS PAPER DESCRIBES A PILOT STUDY that provides rural households in the south-east of Madagascar with access to a water source at the home through the sale of partially subsidized domestic rainwater harvesting (RWH) systems. The pilot examines whether innovative system design and demand-driven financing strategies can produce a supported self-supply at the household level that yields high-quality potable water while maintaining continued system functionality.

Water supply interventions in rural, low-income settings are common but are often plagued by poor functionality (Taylor, 2009; World Bank, 2017). Lack of community ownership and the use of technologies, and materials that are out of step with the needs and capacities of communities are principal drivers of diminishing functionality of water sources over time (World Bank, 2017). Demand responsive approaches that require greater financial input from beneficiaries have been shown to increase long-term functionality (Andres et al., 2016). However, in more isolated rural settings, demand responsive approaches are not always sufficient to bridge the gaps in technical expertise and materials that lead

Harry Chaplin (harry.chaplin@seedmadagascar.org) SEED Madagascar and Hugo Legge (hugo.legge@Ishtm.ac.uk) London School of Hygiene and Tropical Medicine

(c) The authors. This open access article is published by Practical Action Publishing and distributed under a Creative Commons Attribution Non-commercial No-derivatives CC BY-NC-ND license http://creativecommons.org/licenses/by-nc-nd/4.0/ ISSN:0262-8104/1756-3488 
to breakdown in supply. In these instances, interventions at the household level offering a supported self-supply model are a promising but under-researched alternative to community-based approaches.

RWH is a broad term that can be used to describe the practice of collecting and storing rainfall runoff. It has been used across a variety of low-, middle-, and highincome settings as well as in a range of varying climates as a solution to issues of water scarcity and inadequate drinking water quality (Gould and Nissen-Petersen, 1999; Saladin and Bohara, 2016; Peters, 2016). Previous studies have shown that the use of RWH systems as primary sources of drinking water is associated with a reduced risk of diarrhoeal disease in children under five years of age when compared with the use of unimproved sources (Garrett et al., 2008). However, water quality across RWH interventions has been shown to be highly variable and is dependent on a set of design, maintenance, and environmental factors. Among the principal water quality determinants are the use of a first-flush diversion mechanism to self-regulate water quality and the practice of timely operation and maintenance (O\&M) (DeBusk and Hunt, 2014).

The project site was located across four rural communities in the isolated region of Anosy in south-eastern Madagascar. With 85.4 per cent of Anosy's population estimated to be living on less than US\$1 per day, the region has the fifth highest poverty rate in the country (IMF, 2017). As of 2012, over half (53.4 per cent) the population were reliant on surface water as a primary source of drinking water and of these only 13.4 per cent reported treatment of water prior to consumption (INSTAT/UNICEF, 2013). Despite high levels of rainfall throughout the year (140 mm monthly average) (WMO, 1990) RWH has not been widely adopted in the region.

Implementation of the pilot was carried out by SEED Madagascar, a UK-registered charity that focuses on alleviating poverty through programmes that include community health, water, sanitation, and hygiene (WASH), livelihoods, and education. The organization has 18 years' experience working in the project locale, during which time it has implemented a variety of community-based rural water supply projects. Due to a lack of long-term funding the pilot was budgeted to continue for a period of eight months. During this time RWH systems were gradually rolled-out in the target communities and data was collected on system functionality, water quality, and user-fee payments.

\section{Methods}

\section{Finance structure}

The intervention adopted a demand responsive approach, utilizing a supported self-supply model that saw RWH systems marketed and sold to households under a partially subsidized pricing structure. Upon agreement to purchase a system, a contract for a loan agreement was drawn up between the household and the implementing organization and the first of six monthly instalments was paid by the household. Following this, materials for the RWH system were collected by the household from a centrally located store and installation of the system was undertaken by project staff in collaboration with household members. 
Microfinance firms were discounted as a source of financing for the systems due to high interest rates and community concerns surrounding large collateral commitments. The loan agreements drawn up by the implementing organization required no collateral payment and charged no interest. However, once a plan was more than 60 days in arrears it was considered to be in default and materials were reclaimed and the beneficiary refunded 25 per cent of invested funds.

In addition to defaulting on repayments, the contract outlined how the organization retained possession of materials and the right to reclaim materials if reallocated, damaged or sold within the first six months. After completing repayment, a deed of ownership was signed by both parties, which signified the transfer of complete ownership and responsibility of the system to the beneficiary.

In establishing an appropriate pricing level, a thorough willingness to pay (WTP) analysis was undertaken in the target communities. Combining the WTP with system output targets over the proposed 8-month implementation period, the pricing level was chosen at $\operatorname{Ar130,000~(\$ 39.35)~and~Ar160,000~(\$ 48.43)~for~the~systems~with~}$ ravinala (thatched palm) and metal roofs, respectively. These amounts represented 57 per cent of the system market cost, including transport. The outstanding amount was covered by the implementing organization.

\section{System design}

The system design was focused on simplicity, accessibility of materials, and affordability. The systems utilized second-hand, 250-L pre-fabricated plastic containers as storage tanks. RWH supply is limited by the size of the collection area, which in turn defines the upper limits for storage capacity. Design is subsequently refined to a smaller volume by the demand per time period, providing for an efficient allocation of resources in manufacture. However, this approach requires bespoke and more complicated installation by skilled labour than, for example, prefabricated plastic tanks. Given the local availability and affordability of these 250-L containers, the systems were designed to support RWH at this volume. The systems would not be as efficient as a bespoke design but this compromise was deemed acceptable for the purposes of easy and quick installation, assured tank life span, and portability.

The design of the first flush system worked towards the same principles. Locally and cheaply available jerrycans (\$0.76) were adapted to facilitate water conveyance from roof to tank while also trapping debris in the 20-L chamber. A piece of half-cut PVC pipe acted as a funnel to direct the overflowing water from the jerrycan to the holding tank. Cloth covering all outlets of both vessels prevented access by mosquitoes and other contaminants (see Photo 1).

To ensure widespread replicability, two different systems were designed to account for the two common roofing materials used in rural Madagascar: ravinala and corrugated metal. While the metal roofs, painted to delay rusting, used a more conventional approach of plastic guttering (Photo 2), the ravinala roofs warranted an innovative design. Labasy (synthetic leather) was selected for its durability proven in a six-month pre-trial and low price per square metre of Ar8,000/1.4 $\mathrm{m}^{2}$ (\$2.42). 


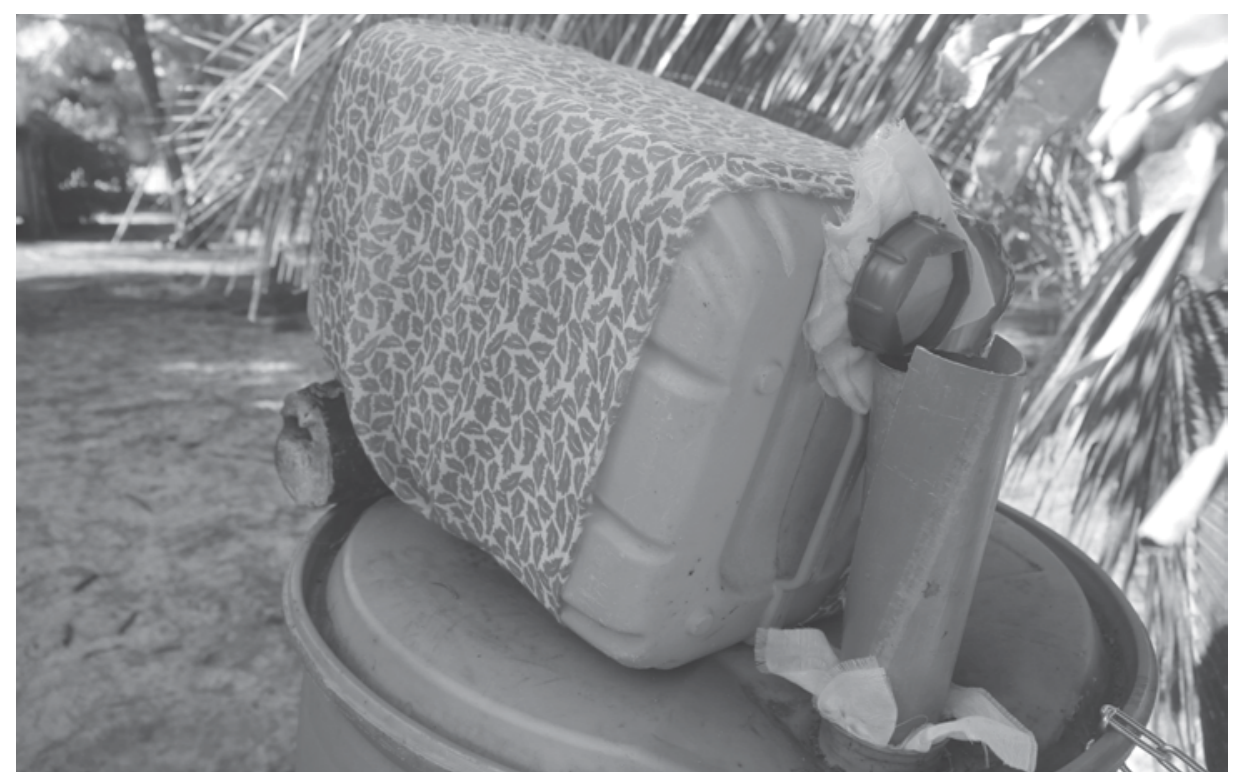

Photo 1 Jerrycan first flush system positioned to convey water to the tank

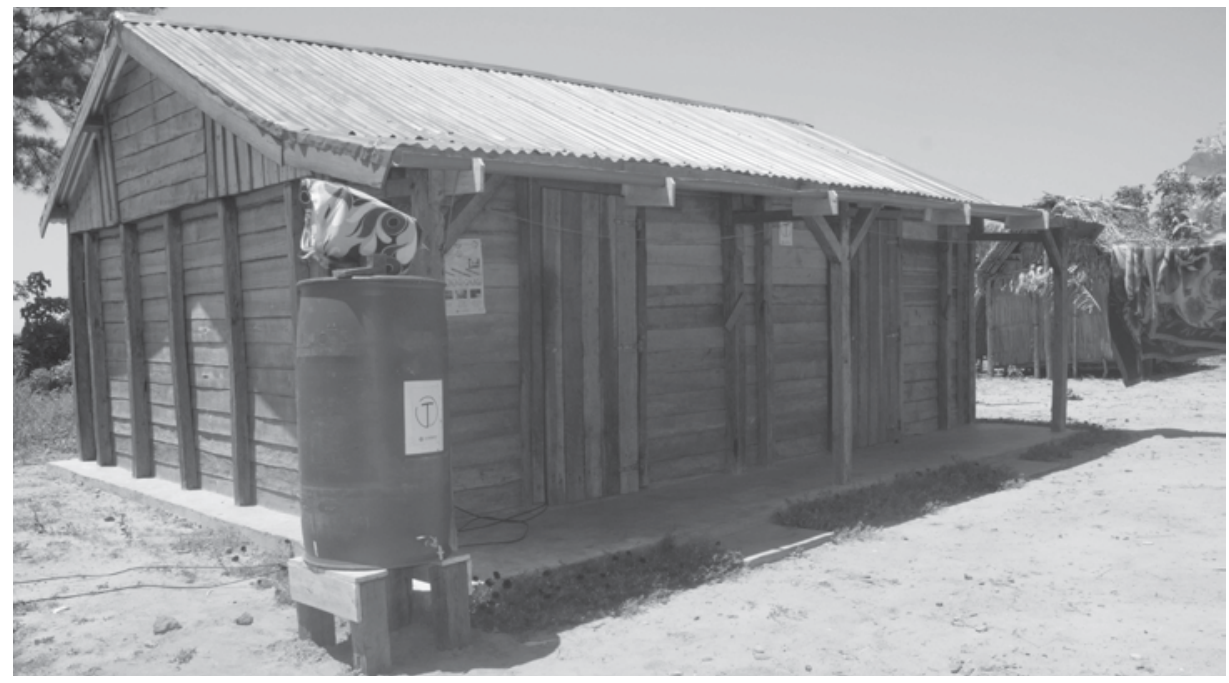

Photo 2 Conventional RWH system using metal roofing and plastic guttering

Three, 2-m overlapping roofing panels with built-in gutters made of this material were tied to the ravinala to ensure a clean and efficient run-off (Photo 3). While the ravinala design was expected to be less efficient and more prone to material degradation, the level of functionality was acceptable for the collection of sufficient quantities of clean water for drinking purposes. 


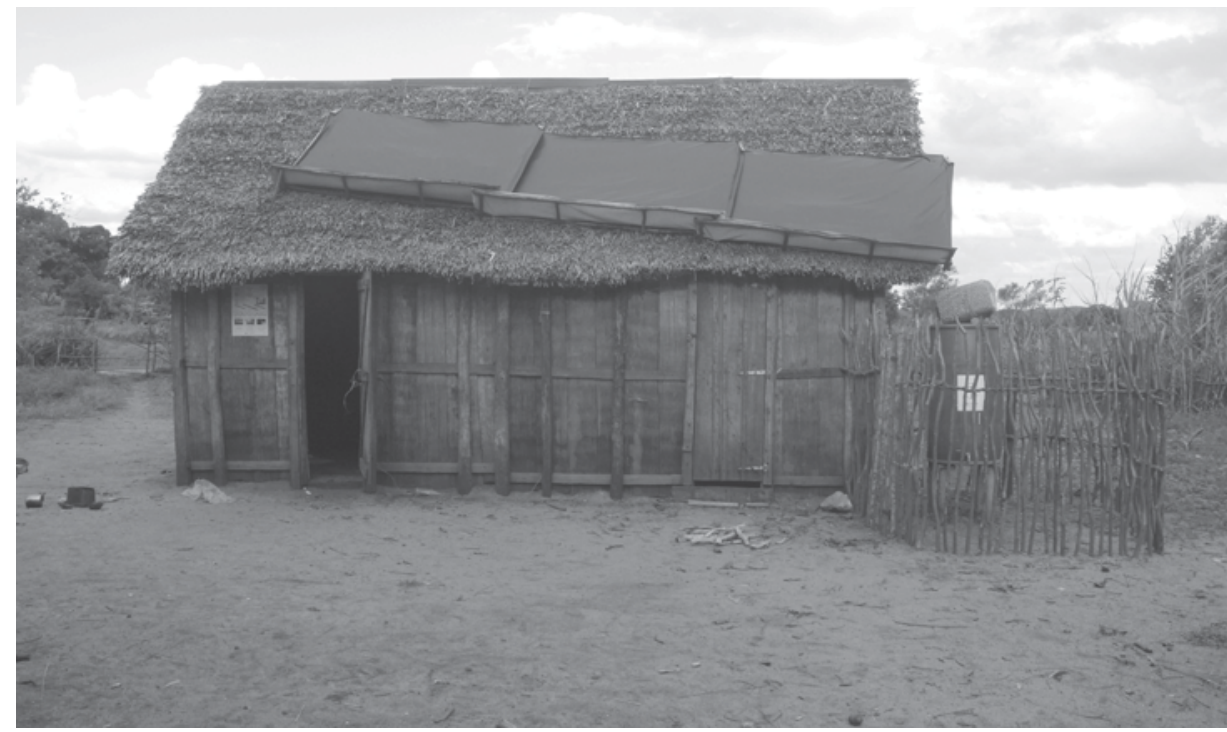

Photo 3 Innovative synthetic leather roofing panels retrofitted to a ravinala house

The final design consideration made was the selection of a galvanized tap, threaded directly into the tank $5 \mathrm{~cm}$ above the bottom to allow a small dead storage. The tap level was raised $40 \mathrm{~cm}$ from ground level to ensure easy access for common collection vessels by the family.

Following each system installation, education seminars were held with each beneficiary household by a trained community liaison officer. These seminars were used to establish a household-specific water safety plan and to ensure that household members were able to effectively operate and maintain their systems.

Overall, key design features influenced a simple system that unskilled beneficiaries were able to operate and repair with locally available materials, contributing to continued functionality and the provision of high quality water. Supplementary treatment of water prior to use was not recommended to beneficiaries. This was because of anticipated low levels of microbial contamination in the knowledge that bacterial count decreases when water is stored within a dark and closed environment (Amin et al., 2013) and the anticipated unacceptability of complicated water treatment methods in the target communities.

\section{Results}

\section{Demand and adherence to repayment plans}

Between September 2017 and April 201820 RWH systems were installed in 15 households across four communities with installations taking place gradually over this period. All beneficiaries opted to repay the cost of the system over a period of six months with monthly instalments averaging Ar25,000 (\$7.57). 
Table 1 Adherence to repayment plans, September 2017 - April 2018

\begin{tabular}{lc}
\hline & Value \\
\hline Total number of payments & 40 \\
Payments on/before due date (\%) & $5(12.5)$ \\
Payments within 7 days of due date (\%) & $21(52.5)$ \\
Payments within 14 days of due date (\%) & $31(75.5)$ \\
Payments within 30 days of due date (\%) & $36(90)$ \\
Payments within 60 days of due date (\%) & $40(100)$ \\
Average day of repayment in relation to due date, mean (SD) & $+8.75(14.9)$ \\
\hline
\end{tabular}

Excluding the first payment (which was paid as a condition of enrolling in the project), payments made during the pilot period were made on average 8.75 days late $(\mathrm{SD}=14.9$ ); 12.5 per cent of payments were paid on or before their due date, 52.5 per cent within seven days of their due date, and 75.5 per cent of payments were paid within 14 days of their due date (Table 1). All payments were made within 60 days of their due date and as a result no households were deemed to have 'defaulted' on their payment plans, thus avoiding material reclamation. Note that the data presented here includes only payments made during the active pilot period between September 2017 and April 2018.

\section{Water quality}

Water quality tests were conducted on a random sample of 12 of the 20 RWH systems in April 2018 (due to limited resources not all systems could be tested). The mean age of sampled systems was 4.2 months ( $\mathrm{SD}=2.03$ ). Microbial and physical parameters were analysed using a DelAgua Water Testing Kit (DelAgua, 2018). The median thermotolerant coliform count was 7 colony-forming units (CFU)/100 ml (interquartile range $(\mathrm{IQR})=1-21$ ) with 66.6 per cent of systems sampled $\leq 10 \mathrm{CFU} / 100 \mathrm{ml}$. Mean conductivity was $10.3 \mu \mathrm{S} / \mathrm{cm}(\mathrm{SD}=5.69), \mathrm{pH}$ was $6.85(\mathrm{SD}=0.048)$, and turbidity and free chlorine were $0.0 \mathrm{NTU}$ and $0.0 \mathrm{mg} / \mathrm{l}$, respectively (Table 2). In comparison, water quality tests carried out by the implementing organization on existing communal water sources in one of the target communities showed $51 \mathrm{CFU} / 100 \mathrm{ml}$ for the community protected dug well and 96 CFU/100 $\mathrm{ml}$ for a commonly accessed body of surface water (SEED, 2016).

\section{Adherence to operation and maintenance}

User adherence to O\&M schedules was determined through regular, unscheduled system checks, which provided a score according to observations of 11 binary indicators on maintenance of the system. A score of zero indicated the absence of any maintenance faults that could potentially impact water quality such as failure to reset the first flush mechanism. Between September 2017 and April 2018, 202 system checks were carried out on 20 systems, with 1.22 faults recorded on average per visit. Over this period, 23 per cent of system checks showed zero maintenance faults, 44 per cent registered one fault, and 32 per cent showed two or more faults (Figure 1). 
Table 2 Summary statistics from water quality tests, April $2018(n=12)$

\begin{tabular}{lc}
\hline & Value \\
\hline Type of roof & \\
$\quad$ Ravinala (thatch) & $2(16.7 \%)$ \\
$\quad$ Metal & $10(83.3 \%)$ \\
Age of system in days at time of sampling, mean (SD) & $127.3(60.92)$ \\
pH level, mean (SD) & $6.85(0.048)$ \\
Turbidity (NTU), mean (SD) & $0.0(-)$ \\
Free chlorine (mg/l), mean (SD) & $0.0(-)$ \\
Conductivity ( $\mu S / c m)$, mean (SD) & $10.3(5.69)$ \\
CFU/100 ml, mean (SD) & $17(29.61)$ \\
$\quad$ Median (IQR) & $7(1-21)$ \\
Max outlier & 106 \\
\hline
\end{tabular}

Source: Project Tatirano water quality tests, April 2018

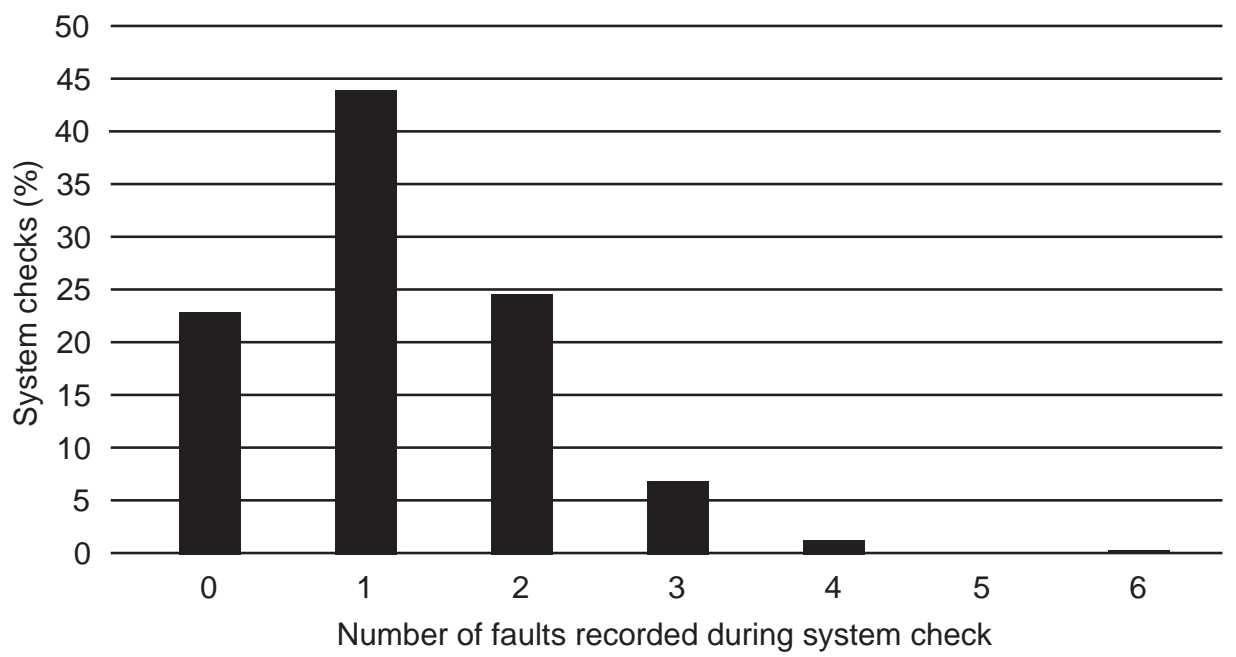

Figure 1 Number of faults recorded during system check, November 17 - April 18

The most common faults recorded were failure to clean the main tank within the past two months (32 per cent), failure to keep the cloth covering the first flush mechanism free from dirt ( 27 per cent), and failure to reset the first flush 24 hours after the last rain (25 per cent) (Figure 2).

\section{Functionality}

Functionality was defined as a system that provided water at the time of a system check. Between March and April (traditionally the wet season) functionality of systems was measured as part of system checks. In total 56 checks were carried 
First flush not reset 24 hours

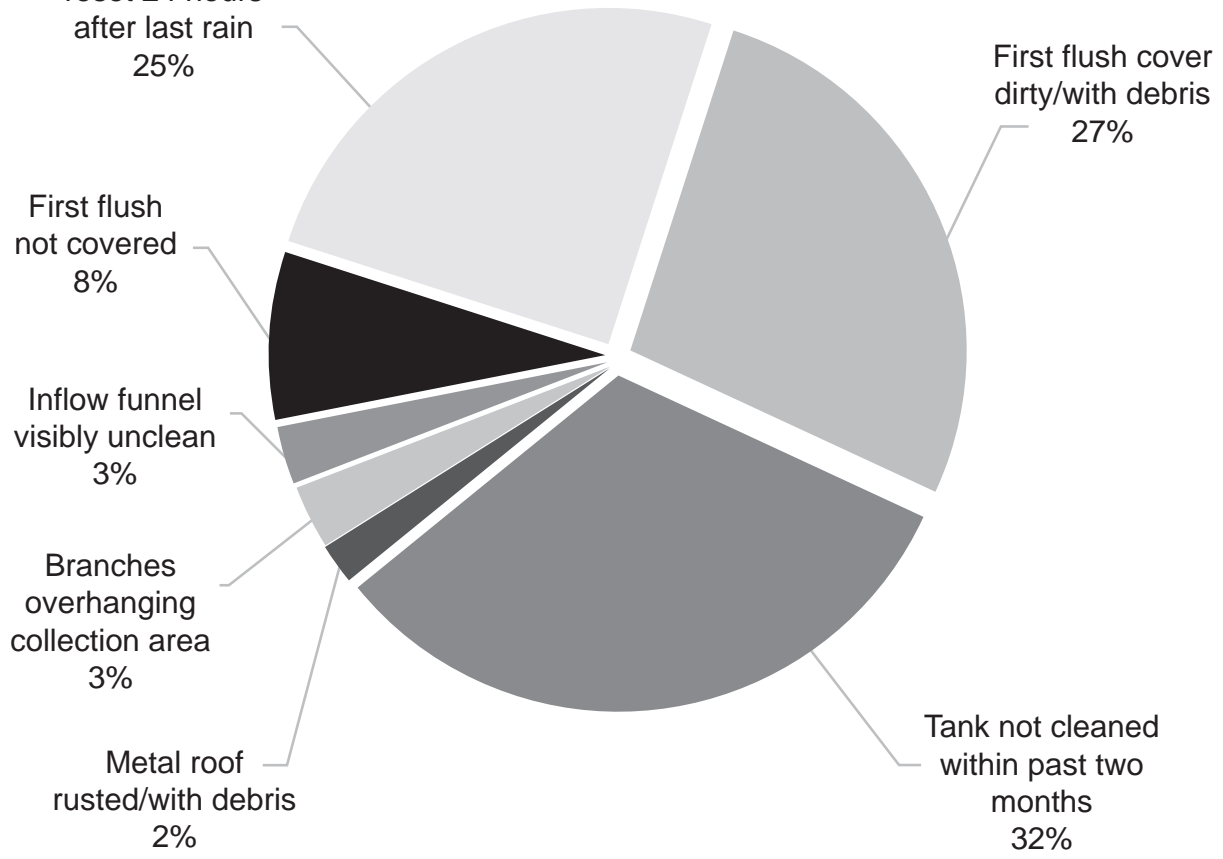

Figure 2 Types of faults recorded during system check, November 17 - April 18

out on 19 systems with an average frequency of 2.9 checks per system over the 33-day period. The results showed that systems were, on average, functional 77 per cent of the time. The lack of functionality was due to the absence of water in the main tank and at no point was a result of material failure.

\section{Discussion}

While these findings saw the intervention fall short of meeting the WHO's drinking water quality guideline of $0 \mathrm{CFU} / 100 \mathrm{ml}$ (WHO, 2017), they do demonstrate its effectiveness in bringing households down from 'high' to 'intermediate' risk in a WHO risk ladder (WHO, 2016). In similar settings where there is a high reliance on unimproved drinking water sources in addition to poor household water treatment and storage practices, an intervention which significantly reduces, rather than eliminates the risk of unsafe drinking water should be considered a relevant tool for public health practitioners.

The high level of O\&M, the lack of mechanical issues causing breakdown in functionality, and the absence of any instances of redistribution of materials, suggest a system design that beneficiaries were both capable and motivated to operate and maintain. These findings indicate that while the system suffered from short-term inadequate continuity of service and losses during heavy rains due to insufficient 
storage capacity, it has great potential for long-term functionality should the tank size be increased. Utilizing locally sourced materials in the design of the system also has implications for the intervention's scalability as the project could be expanded without the necessity for large-scale importation of materials.

With regard to the finance model, the pilot demonstrated that households were prepared to pay a significant amount to receive a non-income-generating water supply in a low-income, water-abundant region. Removing interest and collateral demands, allowing repayments over time on loan plans, and offering favourable terms on repayment defaults likely helped to reduce the risk associated with enrolling in the project.

Adherence to payment plans was strong considering the high relative cost and limited resources of the project staff to collect payments. Flexibility in accepting payments and restructuring payment plans was vital in protecting beneficiaries from default and reclamation of materials. This was particularly important as insecure and irregular incomes propagated repayment issues as many beneficiaries rely on inconsistent seasonal fruit and fisheries harvests for income. However, due to the small scale of the pilot it was difficult to assess the scalability of the financing model. It is likely that a larger-scale intervention utilizing the same in-house loan system would need to allocate significant resources to the management and administration of these loans in order to ensure timely repayment.

Overall the findings from this paper demonstrate a proof of concept for the use of locally adapted, low-tech RWH systems in conjunction with a supported self-supply model at the household level. They show that with a high level of organizational support, such an approach can be used in isolated, low-resource settings as a means to increase access to improved water sources. However, further field trials in other locations should be undertaken at a greater scale and over a longer period to monitor the long-term functionality of such systems and the ongoing acceptability of the financing model.

\section{References}

Amin, M.T., Tschung-il Kim, Amin, M.N. and Han, M.Y. (2013) 'Effects of catchment, firstflush, storage conditions, and time on microbial quality in rainwater harvesting systems', Water Environment Research 85: 2317-29 <http://dx.doi.org/10.2175/106143013X13706200598433>.

Andres, L., Deb, S., Gambrill, M., Giannone, E., Joseph, G., Kannath, P., Kumar, M., Kurian, P.K., Many, R. and Muwonge, A. (2016) Sustainability of Demand Responsive Approaches to Rural Water Supply: The Case of Kerala [pdf], Washington, DC: World Bank Water Global Practice Group <http://documents.worldbank.org/curated/en/283051491326550979/pdf/WPS8025.pdf> [accessed 24 February 2019].

DeBusk, K. and Hunt, W. (2014) Rainwater Harvesting: A Comprehensive Review of Literature [online], North Carolina: Water Resources Research Institute of the University of North Carolina <https://repository.lib.ncsu.edu/bitstream/handle/1840.4/8170/1_NC-WRRI-425. pdf? sequence $=2 \&$ isAllowed $=\mathrm{y}>$ [accessed 24 February 2019].

DelAgua (2018) DelAgua Single Incubator [online] <http://www.delagua.org/products/details/10098DelAgua-Single-Incubator $>$ [accessed 30 August 2018].

Garrett, V., Ogutu, P., Mabonga, P., Ombeki, S., Mwaki, A., Aluoch, G., Phelan, M. and Quick, R.E. (2008) 'Diarrhoea prevention in a high-risk rural Kenyan population through point-of-use 
chlorination, safe water storage, sanitation, and rainwater harvesting', Epidemiology and Infection 136: 1463-71 <http://dx.doi.org/10.1017/S095026880700026X>.

Gould, J. and Nissen-Petersen, E. (1999) Rainwater Catchment Systems for Domestic Supply: Design, Construction and Implementation, Rugby, UK: Practical Action Publishing.

L'Institut National de la Statistique (INSTAT) and United Nations Children's Fund (UNICEF) (2013) Final Report: Madagascar: South Multi-Indicator Cluster Survey (MICS) 2012, Antananarivo, Madagascar: INSTAT.

International Monetary Fund (IMF) (2017) Republic of Madagascar: Economic Development Document [online] <https://www.imf.org/ /media/Files/Publications/CR/2017/cr17225.ashx> [accessed 24 February 2019].

Peters, E.J. (2016) 'Success and success factors of domestic rainwater harvesting projects in the Caribbean', Journal of Sustainable Development 9: 55-69 <http://dx.doi.org/10.5539/jsd. v9n5p55>.

Saladin, M. and Bohara, R.C. (2016) Difficulties in Replicating Success Stories: The Case of Domestic Rainwater Harvesting [pdf], Côte d'Ivoire: Rural Water Supply Network (RWSN) $<$ https://rwsnforum7.files.wordpress.com/2016/11/full_paper_0137_submitter_0046_saladin_ matthias.pdf> [accessed 1 May 2018].

SEED Madagascar (2016) Project Tatirano Phase 1 Final Report [pdf], Fort Dauphin, Madagascar: SEED Madagascar <https://madagascar.co.uk/application/files/1915/1928/3358/Project_ Tatirano_Phase_I_Final_Report_2016.pdf >.

Taylor, B. (2009) Addressing the Sustainability Crisis: Lessons from Research on Managing Rural Water Projects [pdf], Tanzania: WaterAid <https://washmatters.wateraid.org/publications/ addressing-the-sustainability-crisis-lessons-from-research-on-managing-rural-water $>$ [accessed 26 February 2019].

World Bank (2017) Sustainability Assessment of Rural Water Service Delivery Models: Findings of a Multi-Country Review [online], Washington, DC: World Bank <https://openknowledge. worldbank.org/bitstream/handle/10986/27988/W17055.pdf? sequence $=4$ \&isAllowed $=y>$ [accessed 24 February 2019].

World Health Organization (WHO) (2016) Quantitative Microbial Risk Assessment: Application for Water Safety Management [pdf], Geneva, Switzerland: WHO <http://apps.who.int/iris/ bitstream/handle/10665/246195/9789241565370-eng.pdf?sequence $=1>$ [accessed 24 February 2019].

WHO (2017) Guidelines for Drinking-water Quality: $4^{\text {th }}$ Edition, Geneva, Switzerland: WHO <http:// apps.who.int/iris/bitstream/handle/10665/254637/9789241549950-eng.pdf?sequence=1> [accessed 24 February 2019].

World Meteorological Organization (WMO) (1990) 'Country Profile Database: Madagascar Regional Association (Africa)’ [online] <https://www.wmo.int/cpdb/madagascar\#chart_25912> [accessed 30 August 2018]. 